\section{International Scientific Journal Theoretical \& Applied Science}

p-ISSN: 2308-4944 (print) e-ISSN: 2409-0085 (online)

Year: $2016 \quad$ Issue: 9 Volume: 41

Published: $30.09 .2016 \quad$ http://T-Science.org

SECTION 9. Chemistry and chemical technologies.
Victor Goldade

Doctor of Science (Eng), Professor, V.A. Belyi Metal-Polymer Research Institute of National Academy of Science of Belarus; Francisk Skorina Gomel State University,

Gomel, Belarus victor.goldade@gmail.com

Ekaterina Bagryantseva $\mathrm{PhD}$ in Merchandising,

Belarus Trade and Economic University of Consumer's Cooperation, Gomel, Belarus gep07@mail.ru

Olga Ermolovich

$\mathrm{PhD}$ in Chemical technology, Belarus State Transport University, Gomel, Belarus yermolovich@yandez.ru

Valentina Sytsko

Doctor of Science (Eng), Professor, Belarus Trade and Economic University of Consumer's Cooperation, Gomel, Belarus val19-10@mail.ru

\title{
ELECTRICAL STIMULATION OF BIODEGRADATION OF POLYMER PACKING FILMS
}

\begin{abstract}
It was established that adsorptive immobilization of microorganisms on the electret polyethylene films runs faster than on the non-electret ones independently of the adsorbate polarity. Immobilization was found to occur together with the charge carrier transfer from the surface layer traps of the electret film into the structure of the microorganism cells, and neutralization of the charges during metabolism in the cells. The electric intrinsic field of the electret polyethylene films was found to intensify the vital functions of soil microorganisms and promote the accelerated growth of their colonies. The optimal surface charge density range of starch-containing polyethylene films was $4-8 \mathrm{nC} / \mathrm{cm}^{2}$. Named phenomena lead to the accelerated biodegradation of the polymer films. The kinetics of biodegradation of electret and non-electret polymer films by soil microorganisms was found different. Strength of the electret films decreases immediately after burial in soil, because in the competition of polymer aging and accumulation of biodamages in the film the latter process is prevailing. This is why the destruction of the electret films by soil microorganisms takes less time.

Key words: biodegradation, electret, films, microorganisms, polyethylene, starch, wastes.

Language: English

Citation: Goldade V, Bagryantseva E, Ermolovich O, Sytsko V (2016) ELECTRICAL STIMULATION OF BIODEGRADATION OF POLYMER PACKING FILMS. ISJ Theoretical \& Applied Science, 09 (41): 1-10.

Soi: http://s-o-i.org/1.1/TAS-09-41-1 Doi: crossef http://dx.doi.org/10.15863/TAS.2016.09.41.1
\end{abstract}

\section{INTRODUCTION}

Since the 1960ies polymer film wastes have started to be a hazardous source of contamination of the upper soil and coastal waters of world's ocean. This problem is worsening due to a constant growth of their consumption volumes in the form of the packing materials [1]. Degradation of polyolefins in natural conditions that constitute above $40 \%$ of the whole polymer film refuse takes dozens of years [2, $3]$. Biodegradable polymer materials (BPM), created at the end of the $20^{\text {th }}$ century, with controlled lifetime have laid the basis for the optimal, ecologically safe approach to the problem of the polymer waste recovery $[4,5]$. The properties of biodegradable films do not in fact change during the package service life whereupon they are disposed. Under the action of atmospheric factors and soil microorganisms they undergo accelerated physicochemical and biological transformations via joining metabolic processes of the natural biological systems [6-8]. Biodegradable plastics are not dangerous for the environment since the main 
products of their destruction are safe for the ecological equilibrium [9].

The term "biodegradable" is commonly used to denote the materials degraded at least partially by the biological systems. According to ASTM standard D5488-94d and European norm EN 13432-2000, "biodegradable" means "capable of undergoing decomposition into carbon dioxide, methane, water, inorganic compounds, and biomass". Biodegradation is the degradation of an organic material caused by biological activity (biotic degradation), mainly microorganisms' enzymatic action [7].

Today's industry of plastic materials has a range of BPM with a wide spectrum of properties meeting the requirements of different economic spheres. These materials can be subdivided into the following classes according to their structural and technological parameters [10]:

- biodegradable plastics based on natural polymers (polysaccharides, proteins, lignin, etc.) [1113];

- biodegradable polymers synthesized by chemical and microbiological techniques [14-16];

- composite BPM [17-19].

During manufacture of composite BPM, their synthetic polymer binder is most often filled by some natural polymer, e.g. starch, cellulose, chitin, and etc. [20-22]. Biodegradable materials based on polyethylene and its copolymers, polypropylene, $\gamma$ butyrolactone and natural polymers are in great demand in today's market. Most important advantage of these materials is their lower cost as compared to the non-modified synthetic polymers. They are not so costly because the recovered vegetable raw stock used as biodegradable filler is 2 to 3 times cheaper than the binders. Development of composite BPM with a high degree of biopolymers content became a main way of plastics biodegradation ensuring. But this way is connected with technology complication and worsening of film properties. It is reasonable to suggest that on this way the chemical-technological reserves of biodestruction degree increase are exhausted.

New in principle approach to solution of the problem of biodegradation of polymeric wastes consists in transformation of polymer materials and their products into the electret state. An electret is the electric analogue of magnet, i.e., it is a dielectric generating a permanent electric field in the neighboring space [23]. Thermoplastic polymers are typical dielectrics. They acquire a stable electret charge during extrusion without application of any external electromagnetic effects. The spontaneous electret state is intrinsic for the polymer fibers [24], polymer blends [25], and filled plastics [26]. Microorganisms are extremely sensitive to any changes in the external electromagnetic field. The weak electric field of the polymer films and fibers (the surface charge density is about a few $\mathrm{nC} / \mathrm{cm}^{2}$ ) intensifies adsorptive immobilization of microorganisms and exerts an essential effect on bacteria metabolism, thus accelerating their growth. It makes sense to electrify polymer disposables since electrization does not alter their service properties but assists significantly in multiplication of the microorganisms destroying the polymer macromolecules. The method of converting polymer materials and goods into the electret state can make a base for a new modern trend in reclamation of polymer wastes.

The way microorganisms respond to the electric field is not yet fully understood. It is believed that cells polarized in the electric field are brought into the adsorptive-electrostatic interaction with the electret substrate during which the field changes the elementary forms of motion of the ions, polar molecules, double electrical layers and so on.

The purpose of the present work was to disclose the principles of microorganisms immobilization on the electret polymer films and to study how the intrinsic electric charge of the films affects their biodestruction kinetics by the soil microorganisms.

\section{EXPERIMENTAL}

\subsection{Materials}

In our experiments we have used low-density polyethylene (PE) (Russian State Standard GOST 16337, PE grade 15803-020), corn starch (St, GOST 7697), and inorganic salts: ammonium sulfate $\left(\mathrm{NH}_{4}\right)_{2} \mathrm{SO}_{4}$ and potassium dihydrophosphate $\mathrm{KH}_{2} \mathrm{PO}_{4}$. These salts are traditionally used as components of culture mediums for the microorganisms cultivation, they are heat-resistant and endure co-extrusion with polymers. They are known as biogenic fillers for polymeric carriers of the microorganisms able to accelerate immobilization and biofilm growth on the carriers [27].

The polymer compositions were prepared by mechanical mixing of the ingredients and granulation. The granulate was used further to form $100 \pm 5 \mathrm{mcm}$ thick films on a hose film machine.

To study immobilization of microorganisms on the film we have used yeast of Saccharomyces family as a model culture as they have no pathogenic forms among the species of this family. Besides, they are eukaryotic (nuclear) cells that are widely applied in food industry (brewing, bread baking, production of vitamins, and etc.).

In the experiments on studying immobilized microorganisms, we have also used associations of soil microorganism-destructors isolated from the universal soil. The soil presents a mixture of turf, humus, fertilizers and biological dopes. This culture was grown in Petri dishes on a mineralized nutrient medium wherein the films under study were placed. The dishes with the samples were endured in a thermostat under $T=26 \pm 2^{\circ} \mathrm{C}$, after which the 
growth rate of the microorganisms was visually recorded following the Russian Standard GOST 9.049 (Polymer materials and their components. Methods of laboratory tests for mould resistance).

\subsection{Investigation methods}

Circular $(10 \mathrm{~mm})$ film samples used in the immobilization experiments underwent annealing to remove the technological charge. The samples were then electrified in dc corona discharge with varying field intensity $(2 \div 5) * 10^{5} \mathrm{kV} / \mathrm{m}$. The efficient surface charge density $\sigma_{e f}$ of the films was controlled (GOST 25209) by the methods of the vibrating electrode and by the electret-thermal analysis (ETA). The ETA is one of the most informative methods for studying the electret charge in the condensed media. Its essence consists in recording the kinetic parameters of charge relaxation. Charge relaxation in solid dielectrics proceeds rather slowly in usual conditions therefore it is expedient to use thermal stimulation in the electret studies. The temperature dependence of thermally stimulated currents (TSC), called in the physics of dielectrics the TSC spectrum, helps to understand the mechanisms of generating the electret effect.

The TSC spectra of the electret films were obtained by the method described in our paper before [28]. The film sample was placed onto grounded aluminum electrode and was covered by a Teflon film overlaid with another aluminum electrode. The current in the electrode-film- electrode circuit was recorded during heating the system at a $5^{\circ} \mathrm{C} / \mathrm{min}$ rate.

We have recorded the currents generated under thermally stimulated depolarization (at $2,5^{\circ} \mathrm{C} / \mathrm{min}$ heating rate) of the culture fluid drops with suspended in them Saccharomyces cells in a series of experiments using the method described in [29]. The TSC spectra shown hereinafter are the result of at least ten replicate tests averaged by a software used for statistical processing of spectra.

Crystallinity of the films having different compositions was determined by the X-ray diffraction analysis in the monochromatic $\mathrm{CuK}_{a}$ radiation by the X-ray diffractometer DRON-3M (Burevestnik, Russia).

To study physicochemical interactions between the constituents of the films and assimilation of biogenic components by the microorganisms we have used the IR spectroscopy (Specord-80, Carl Zeiss Jena).

The degree of biodestruction of the films was estimated by monitoring breaking stress at tension as related to their endurance time in soil. The films were cut in the form of spatulas of standard sizes (GOST 14236) and were placed into the cups with a soil to $3-5 \mathrm{~cm}$ depth. Once a week, the soil was watered. The samples were periodically removed from the soil and tested on a tearing machine Instron.

The results of experiments cited below were processed by the methods of mathematical statistics (confidence intervals and standard deviations were controlled).

\section{RESULTS AND DISCUSSION}

\subsection{Microorganism's immobilization}

The polymer films charged in the negative corona discharge have shown a peak of the positive current on the TSC spectra (Figure 1a). This peak corresponds to liberation of the charge carriers during the heat-induced destruction of the $\mathrm{PE}$ crystalline structure (melting point $T_{\mathrm{m}}=107^{\circ} \mathrm{C}$ ). The stronger was the intensity of the polarizing field the higher was the peak. The "halo" of the positive current with a maximum at $T \approx 60^{\circ} \mathrm{C}$ corresponds to relaxation of the surface charge localized on the film defects.

When the films are charged in the positive corona discharge (Figure $1 b$ ) the peak corresponding to the PE melting point shows a negative polarity. Two "halos" of opposite polarity of the surface charge with the maxima at about 65 and $80^{\circ} \mathrm{C}$ were also detected. These "halos" resulted from relaxation of heterocharge (charge of the opposite sign) field which was directed against polarizing field [26]. The most likely interpretation of these peaks is the following: During TSC, at about $65^{\circ} \mathrm{C}$, the internal field due to the surface charge aligns some additional dipoles in the film. This process yields a positive peak. At $80^{\circ} \mathrm{C}$, the dipole alignment is thermally destroyed, yielding a negative peak. This latter peak has the same polarity as the peak at about $110^{\circ} \mathrm{C}$ caused by internal drift of the surface charges.

The endurance of the polarized films of both signs in water has resulted, firstly, in a noticeable drop of the peak at $T \approx 110^{\circ} \mathrm{C}$ and, secondly, in a complete disappearance of the surface charges and the corresponding "halos".

The TSC spectrum of the culture fluid containing Saccharomyces cells (Figure 1c, curve 7) looks like a positive "halo" with a maximum at $T=$ $60 \div 70^{\circ} \mathrm{C}$. It corresponds to liberation of the charges due to protein denaturation and thermal destruction of the lipids incorporated in the membranes and cell protoplasm. The temperatures of these processes are a bit higher than those of the surface charge relaxation of the electret films. 


\begin{tabular}{|c|c|c|c|c|c|c|}
\hline Impact Factor: & $\begin{array}{l}\text { ISRA (India) } \\
\text { ISI (Dubai, UAE } \\
\text { GIF (Australia) } \\
\text { JIF }\end{array}$ & $\begin{array}{l}=1.344 \\
=0.829 \\
=0.564 \\
=1.500\end{array}$ & $\begin{array}{l}\text { SIS (USA) } \\
\text { PИНЦ (Russia) } \\
\text { ESJI (KZ) } \\
\text { SJIF (Morocco) }\end{array}$ & $\begin{array}{l}=0.912 \\
=0.234 \\
=1.042 \\
=2.031\end{array}$ & $\begin{array}{l}\text { ICV (Poland) } \\
\text { PIF (India) } \\
\text { IBI (India) }\end{array}$ & $\begin{array}{l}=6.630 \\
=1.940 \\
=4.260\end{array}$ \\
\hline
\end{tabular}
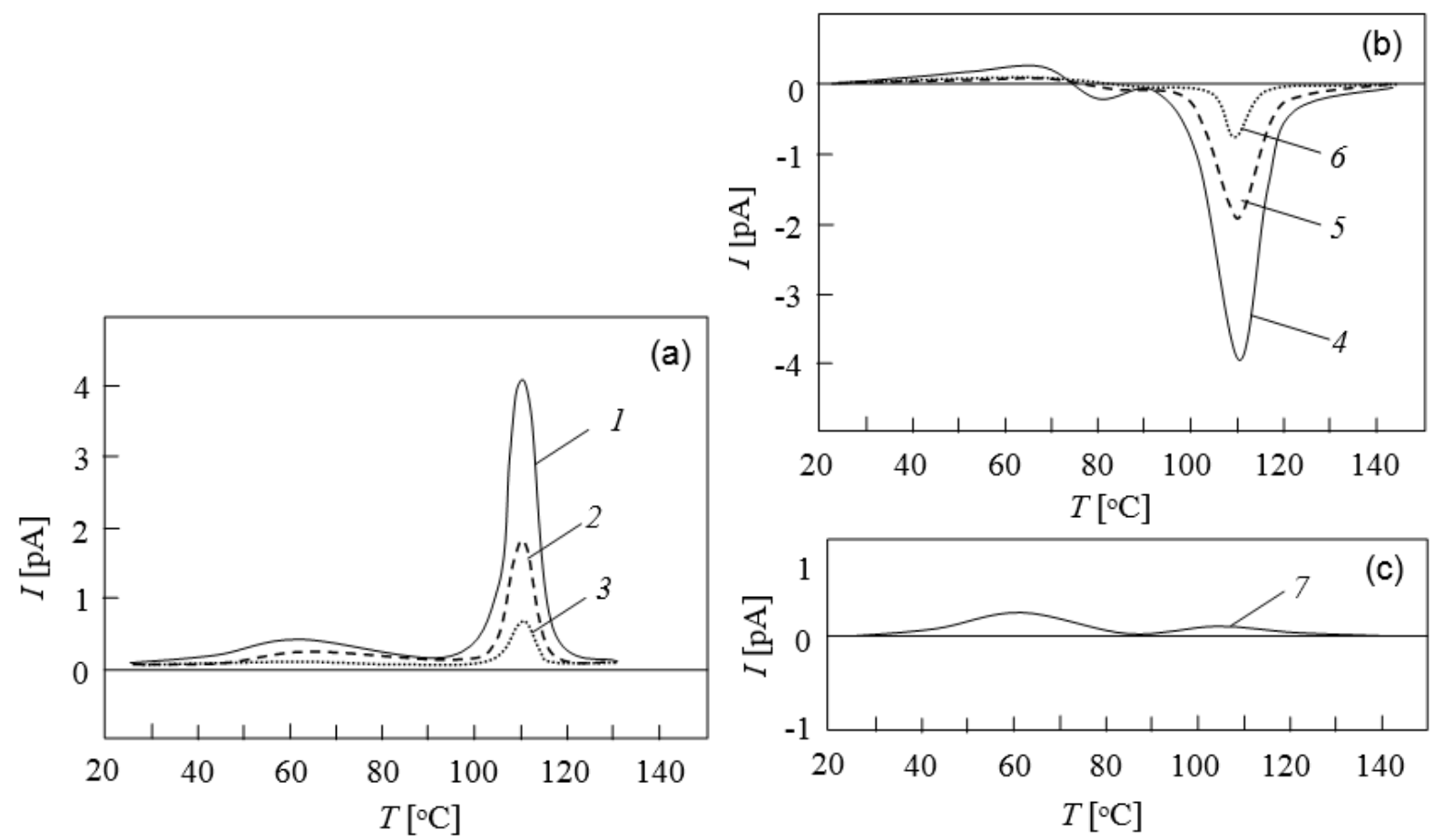

Figure 1 - TSC spectra: $a$ - PE films subjected to a negative corona discharge, curves 1, 2 and 3 correspond to field intensity $E=-12,-6$ and $-4 \mathrm{kV} / \mathrm{cm} ; b-\mathrm{PE}$ films subjected to a positive corona discharge, curves 4,5 and 6 correspond to $E=+12,+6$ and $+4 \mathrm{kV} / \mathrm{cm} ; c$-drop of the culture fluid with Saccharomyces cells (curve 7).

Exposure of the films in the culture fluid leads to the reduction of the electret charge density. The analysis of the TSC spectra of the films subjected to the corona discharge of unlike polarity $-12 \mathrm{kV} / \mathrm{cm}$ and $+12 \mathrm{kV} / \mathrm{cm}$ (Figure 2) has revealed the following.

First, the current peaks corresponding to $T_{\mathrm{m}}$ of the PE have reduced after the first day of exposure in the culture fluid (curves 2 and 6 ). Secondly, a "halo" has appeared on the spectra in the region $50-80{ }^{\circ} \mathrm{C}$ and its area has been expanding till some limits with exposure time. Thirdly, the "halo" has disappeared with washing of the biofilms away from the polymeric substrate (curves 4 and 8 ).

Evidently, adsorption of cells from the culture fluid on the film substrate goes together with neutralization of the charge carriers entrapped in the surface layer of the film. The fact that the large peak on the TSC spectra decreases independently of the substrate charge sign is a confirmation to the presence of both positively and negatively charge areas in the cells participating in the electrostatic interaction with the substrates.

As we have mentioned earlier, the surface charge disappears fully when the films were exposed in water. Consequently, the "halo" of the positive currents at $30-90{ }^{\circ} \mathrm{C}$ presented in Figure 2 complies with denaturation of proteins, enzymes, polypeptides and lipids found in the composition of the cells. This is confirmed by coincidence of the form and typical for the "halo" temperatures presented in Figures $1 c$ and 2 (curves 2, 3,6 and 7). The "halo" vanishes as soon as the biofilm is washed away.

The height of the main peak on the TSC spectra that complies with thermal decomposition of the PE crystalline structure reduces during exposure of the film in the culture fluid (Figure 2). It looks as if crystallinity of the films reduces. But the control measurements of the X-ray crystallinity of the film substrates before and after immobilization of microorganisms have proved it to be invariable. It means that the electrically unbalanced cells adsorbed in the sites of the substrate where unlike charges are localized have neutralized them. The removal of the biofilms from the substrates does not irreversibly rise the peak. Therefore, the charge carriers entrapped in the PE crystalline structure undergo annihilation during immobilization of the cells. Apparently, the charge carriers are travelling during metabolic processes from the traps into the cellular structure and are neutralized there. 


\begin{tabular}{l|lrl|l|ll} 
& ISRA (India) & $=\mathbf{1 . 3 4 4}$ & SIS (USA) & $=\mathbf{0 . 9 1 2}$ & ICV (Poland) & $=\mathbf{6 . 6 3 0}$ \\
Impact Factor: & ISI (Dubai, UAE) $=\mathbf{0 . 8 2 9}$ & PUHL (Russia) $=\mathbf{0 . 2 3 4}$ & PIF (India) & $=\mathbf{1 . 9 4 0}$ \\
& GIF (Australia) & $\mathbf{0 . 5 6 4}$ & ESJI (KZ) & $=\mathbf{1 . 0 4 2}$ & IBI (India) & $=\mathbf{4 . 2 6 0}$ \\
& JIF & $\mathbf{1 . 5 0 0}$ & SJIF (Morocco) & $=\mathbf{2 . 0 3 1}$ & & \\
\hline
\end{tabular}
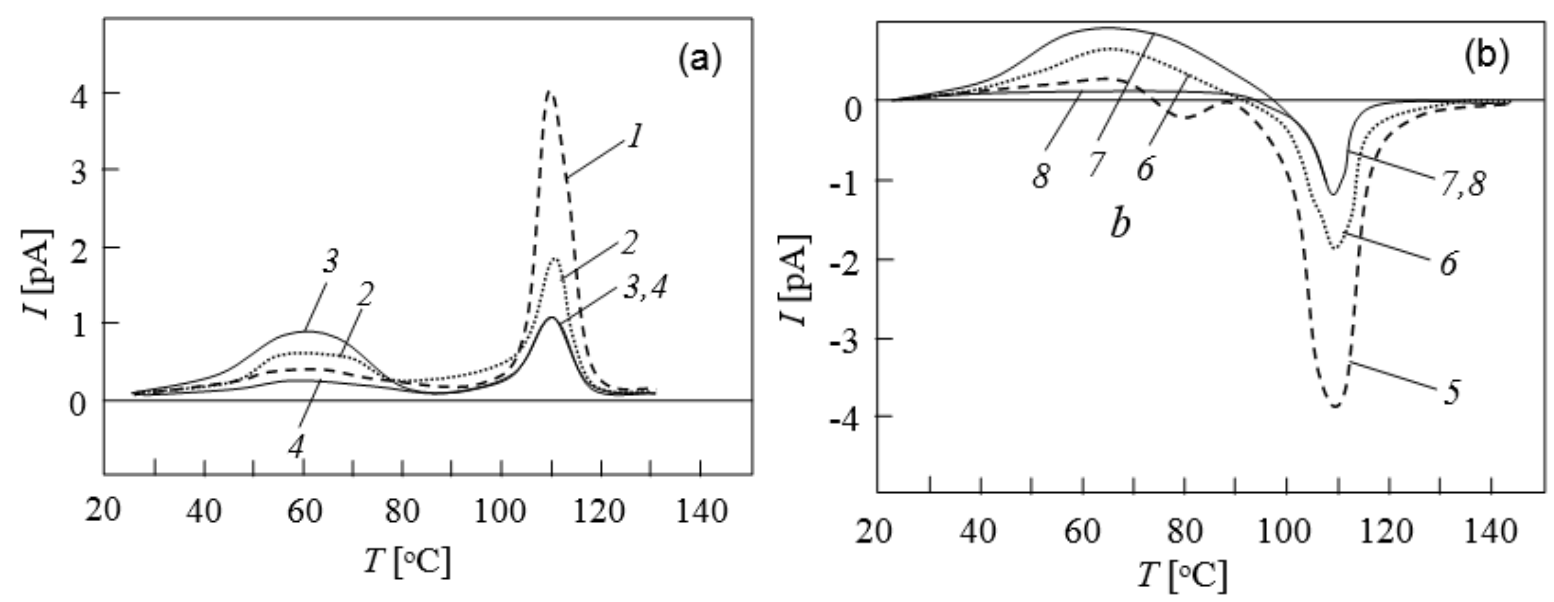

Figure 2 - TSC spectra of PE films charged in corona discharge of the negative (a) and positive (b) signs: 1 and 5 - initial, 2 and 6 - after a day of exposure in culture fluid, 3 and 7 - after 2 days of exposure, 4 and 8 the same with the washed away biofilm.

\subsection{Biofilm growth}

We have estimated the electret charge effect on the microflora growth immobilized on the films by the extent the film samples overgrow with the soil microorganism culture. The intensive growth of the colonies was observed around all electret samples of the initial $\mathrm{PE}$ and its compositions $\mathrm{PE}+$ starch and $\mathrm{PE}+\mathrm{KH}_{2} \mathrm{PO}_{4}$, in contrast to the non-electret films. This confirms the fact that the electric intrinsic field of the films intensifies metabolism of the microorganisms and growth of the colonies. Figure 3 illustrates the dependence of zone width $L$ of microorganisms colonies intensive growth around the film samples on the surface charge density $\sigma_{\mathrm{ef}}$ of the films. The optimal value of charge density ranges from 4 to $8 \mathrm{nC} / \mathrm{cm}^{2}$.

It is observed from Figure 4, that the spectra of the polymer composites $\mathrm{PE}+$ starch display the absorption bands of polysaccharides characteristic for the - $\mathrm{OH}$ group, i.e. the broad and intensive bands of valence vibrations in the region $3600-3200 \mathrm{~cm}^{-1}$, and characteristic bands in the region $1646-1644 \mathrm{~cm}^{-}$ 1. Strong absorption in the region $1200-1000 \mathrm{~cm}^{-1}$ and in the configuration-sensitive region 900-800 $\mathrm{cm}^{-1}$ characterize the vibrations of the starch molecular skeleton [30].

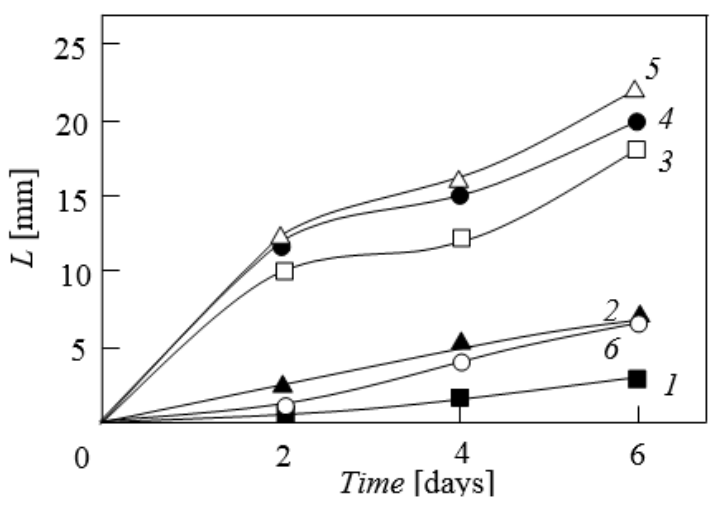

Figure 3 - Time dependence of zone width $L$ of film samples overgrowing by microorganisms at different value of surface charge density of starch-containing $\mathrm{PE}$ films $\sigma_{e f}\left(\mathrm{nC}_{\mathrm{cm}} \mathrm{cm}^{2}\right) 1-\mathbf{0 , 2}-2,3-4,4-6,5-8,6-$ $10 \mathrm{nC} / \mathrm{cm}^{2}$. 


\begin{tabular}{|c|c|c|c|c|c|c|}
\hline Impact Factor: & $\begin{array}{l}\text { ISRA (India) } \\
\text { ISI (Dubai, UAE } \\
\text { GIF (Australia) } \\
\text { JIF }\end{array}$ & $\begin{array}{l}=1.344 \\
=0.829 \\
=0.564 \\
=1.500\end{array}$ & $\begin{array}{l}\text { SIS (USA) } \\
\text { PИНЦ (Russia) } \\
\text { ESJI (KZ) } \\
\text { SJIF (Morocco) }\end{array}$ & $\begin{array}{l}=0.912 \\
=0.234 \\
=1.042 \\
=2.031\end{array}$ & $\begin{array}{l}\text { ICV (Poland) } \\
\text { PIF (India) } \\
\text { IBI (India) }\end{array}$ & $\begin{array}{l}=6.630 \\
=1.940 \\
=4.260\end{array}$ \\
\hline
\end{tabular}

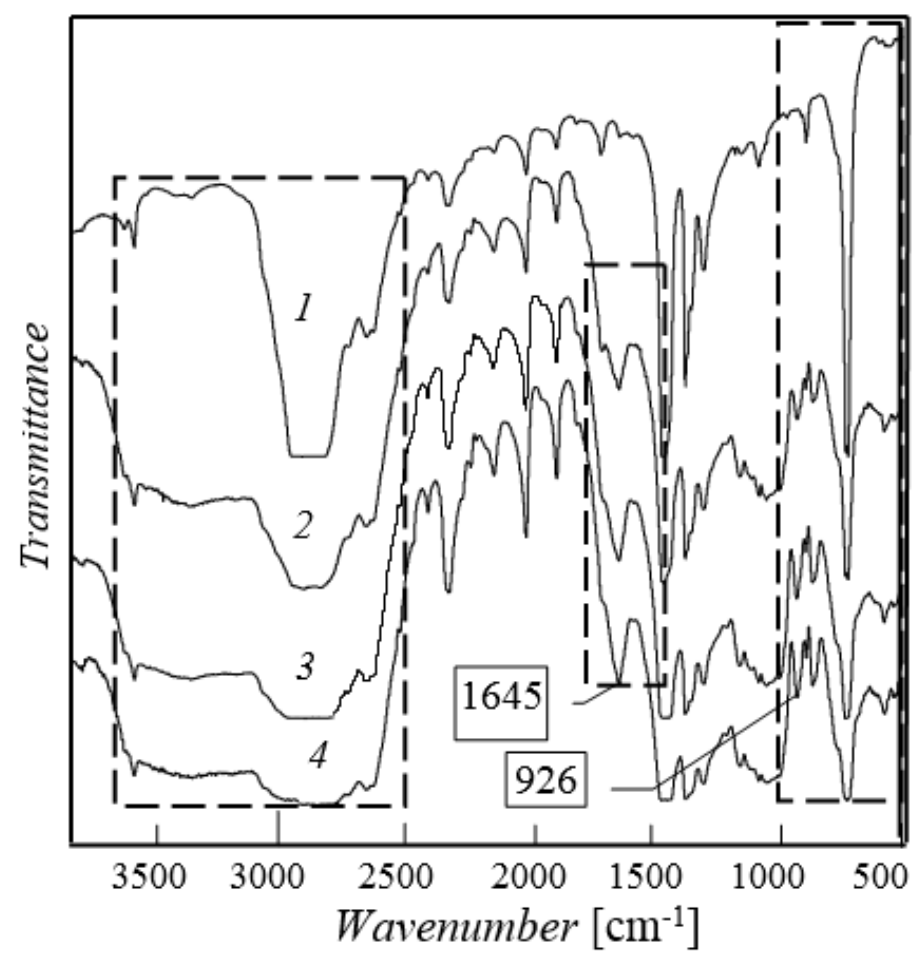

Figure 4 - IR spectra fragments of film samples:

1 - from initial PE; 2 - non-electret composition PE + starch (10\%); 3 - electret of similar composition; 4 - electret of similar composition after exposure in soil (for 6 months)

The IR spectral analysis of the film samples 2 and 3 in the initial state and after their exposure in soil (sample 4) has shown that the electret composite films contain polysaccharide with a deep amorphization degree [31]. This is confirmed, in particular, by changes in the IR spectra intensity in the $1476 \mathrm{~cm}^{-1}$ and $730 \mathrm{~cm}^{-1}$ regions. So, we can state that a recombination of the supramolecular structure takes place in PE which become apparent in the effect of intensity smoothing of so-called "crystallinity bands" seen after starch introduction into the composition (samples 2 and 3), and after starch assimilation by soil microorganisms (sample 4).

Broadening of the band and reduction of the valence vibration intensity in the region of 3600$3000 \mathrm{~cm}^{-1}$ for samples 3 and 4 confirms that polysaccharide hydrogen bonds in the initial system are partially reordered and reconstructed under the electret charge effect, which results in increase of the number of hydroxyl groups available for hydration. The fact of starch amorphization is supported by variations in the absorption band intensities at 1645 $\mathrm{cm}^{-1}$ (characterizes $\mathrm{C}=\mathrm{O}$ bond) and $926 \mathrm{~cm}^{-1}$ frequencies (characterizes $\alpha-1-4$ glycosidic starch linkage). To interpret the IR spectra qualitatively in specified regions we have measured their optical density and compared to the one of the absorption band at 720 (valence vibrations of groups $-\mathrm{CH}_{2}-$ ) chosen as a reference one [32]. The analysis of the relationship between optical densities of the absorption bands under study has brought us to a conclusion that the absorption band at $1645 \mathrm{~cm}^{-1}$ has expanded by $20-25 \%$ in the electret sample 3 as compared to sample 2 , and by $50-55 \%$ in the electret sample 4 after exposure in soil in contrast to sample 3. This proves amorphization of polysaccharide due to the electret charge effect on the supramolecular structure of starch (sample 3), which accelerates further decomposition of starch by soil microorganisms (sample 4). So, it is evident that biodestruction of the samples in soil is intensified by the presence of the electret charge in starchcontaining polymeric films.

Considerable changes in the IR spectra have been recorded also when PE films were doped with such fillers as inorganic salts known to be a source of energy for the microorganisms. This filling results in the intensity growth and a shift to a lower mode number of the peak $1077 \mathrm{~cm}^{-1}$ corresponding to oscillations of the oxidized molecular groups (with a $\mathrm{C}-\mathrm{O}$ bond). In the case $\mathrm{PE}$ is filled with potassium hydrophosphate, this peak shifts to the region of $1050 \mathrm{~cm}^{-1}$ due to phosphorus tailing to the oxidized groups and formation of $\mathrm{P}-\mathrm{O}-\mathrm{C}$ and $\mathrm{P}-\mathrm{OH}$ bonds. 
Ammonium sulfate, used as a filler, shifts the peak to the region of $1060 \mathrm{~cm}^{-1}$, which corresponds to the valence vibrations of the $\mathrm{S}=\mathrm{O}$ bond. However, characteristic peaks $\mathrm{KH}_{2} \mathrm{PO}_{4}\left(850,1080,1300 \mathrm{~cm}^{-1}\right)$ and $\left(\mathrm{NH}_{4}\right)_{2} \mathrm{SO}_{4}\left(600,1060,1400 \mathrm{~cm}^{-1}\right)$ overlap with peaks of the PE vibration spectra. Thus, it is hard to detect the difference in assimilation rates of inorganic salts by microorganisms in the electret and non-electret films by means of IR spectroscopy. This can be easily done by estimating their strength loss.

\subsection{Biodegradation of films}

As of now the biological mechanisms and stages of polymer degradation by soil microorganisms have been established. Biodegradation of starch-filled films begins with assimilation of starch particles on the film surface by the microorganisms and formation of the pores instead of particles, as a result of which the film looses its mass. The threads and conidial fungi heads forming colonies cover the film. The polymeric material experiences embitterment and cracking due to the invasion of mycelium and pore clogging by the metabolic products. Using the electret-thermal analysis the relaxation transitions in polysaccharides were identified [33] along with sorption of soil moisture by the film and microbiological failure of starch structure. Assimilation of starch particles opens way for the microorganisms to the least ordered interfacial areas at the PE-starch interface.

Nevertheless, strength of the electret films initially is increasing when exposed in soil (Figure $5 a$, curve 1) This is possible due to migration of stabilizers from the film, plasticizing effect and chemical action of humic acids found in soil that initiate secondary crystallization of $\mathrm{PE}$ and its macromolecular cross-linking $[3,6]$. Strength of the films decreases afterwards exponentially in time with increasing amount of microbial damage. After 9-10 months of endurance in soil the film looks like a brittle perforated structure, and its strength approaches zero. We may consider the problem of creating biodegradable films solved since the resultant structure is penetrable for water and air, it is safe for the living beings and does not affect environmental equilibrium. The final stages of biodestruction of the film are decomposition of separate film fragments till the end products in the form of water and $\mathrm{CO}_{2}$.
The kinetics of biological decomposition of the electret films is essentially different (Figure $5 a$, curve 2). The original strength of the electret films is higher than that of the non-electret ones since the formation of the polarizing charges is accompanied by structural ordering of the polymer binder [26]. Loss of strength starts immediately after burial in earth. It follows that the intrinsic field of the film induces the activating effect on the kinetics of adsorption immobilization of microorganisms, their metabolism intensity and growth rate, and vital functions of their colonies grown on the film. This does not mean that aging processes leading to restructuring of the film have stopped. The competing process of macromolecular breaking by the microorganisms-destructors are more intensive than those of film strengthening. As a result, the period of biodestruction of the films in soil shortens by the time during which strengthening of the nonelectret films and their further weakening till the initial strength value takes place (Figure $5 a$, period $\square 0)$.

Figure $5 b$ illustrates the initial areas of microbial changes in the film strength with time. Both non-electret PE films (diagram 3) and the ones filled by the salts giving energy for microorganisms $(5,7)$ display almost a similar strengthening rate independently of the film composition. Transfer of the films into the electret state results in their strength loss immediately after their exposure in soil $(4,6,8)$. The rate of this process is conditioned by the nature and concentration of the biogenic filler, as well as its electric conductivity that defines the value of the polarizing charge formed in the film.

Figure $5 c$ shows the similar dependencies for the starch-filled PE film. The strengthening rates of the films with different filling degrees (curves 9 and 10) are different because the content of PE in them is also different. The strength loss with 5 and $10 \%$ filling degrees (10 and 12) differs insignificantly because a similar relation is observed in the velocity of two competing processes: i) aging, cross-linking of macromolecules and strengthening of PE in soil; ii) microbial damage of the films compensating the strengthening effect. 


\begin{tabular}{l|lrl|l|ll} 
& ISRA (India) & $=\mathbf{1 . 3 4 4}$ & SIS (USA) & $=\mathbf{0 . 9 1 2}$ & ICV (Poland) & $=\mathbf{6 . 6 3 0}$ \\
Impact Factor: & ISI (Dubai, UAE) $=\mathbf{0 . 8 2 9}$ & PUHU (Russia) $=\mathbf{0 . 2 3 4}$ & PIF (India) & $=\mathbf{1 . 9 4 0}$ \\
& GIF (Australia) & $\mathbf{0 . 5 6 4}$ & ESJI (KZ) & $=\mathbf{1 . 0 4 2}$ & IBI (India) & $\mathbf{4 . 2 6 0}$
\end{tabular}
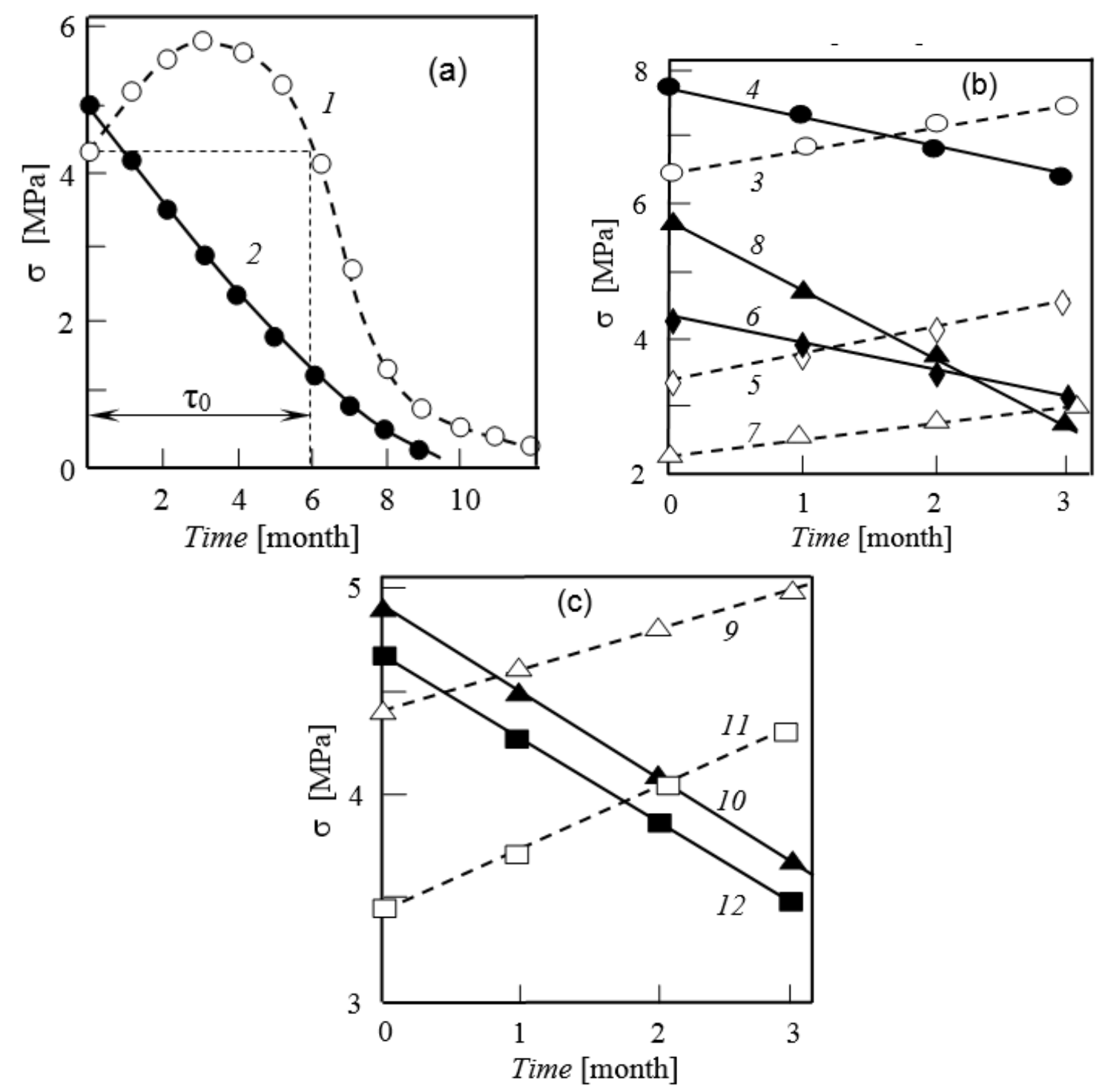

Figure 5 - Strength variation of the films of different compositions during exposure in soil for 8 months (a) and 3 months (b, c): 1, 2 - PE + starch (20\%); 3, 4 - PE; 5, $6-\mathrm{PE}+\mathrm{KH}_{2} \mathrm{PO}_{4}(5 \%)$; 7, 8 - PE + $\left(\mathrm{NH}_{4}\right)_{2} \mathrm{SO}_{4}(5 \%) ; 9,10-\mathrm{PE}+\operatorname{starch}(5 \%) ; 11,12-\mathrm{PE}+\operatorname{starch}(10 \%)$. Dashed line indicated non-electret

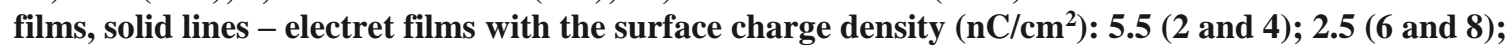
6.0 (10 and 12)

\section{CONCLUSION}

It was established by electret-thermal analysis that adsorptive immobilization of microorganisms on the electret PE films runs faster than on the nonelectret ones independently of the adsorbate polarity. Immobilization was found to occur together with the charge carrier transfer from the surface layer traps of the electret film into the structure of the microorganism cells, and neutralization of the charges during metabolism in the cells. These findings can be used to improve manufacturing technologies for biodegradable films and biotechnological processes.

The electric intrinsic field of the electret PE films was found to intensify the vital functions of soil microorganisms and promote the accelerated growth of their colonies. The analysis of IR spectra of biodegradable electret starch-filled films has shown that polysaccharides undergo amorphization due to the electret charge formation in the films and the effect of soil microorganisms. The optimal surface charge density range of starch-containing polyethylene films is $4-8 \mathrm{nC} / \mathrm{cm}^{2}$. Named phenomena lead to the accelerated biodegradation of the polymer films. 
The kinetics of biodegradation of electret and non-electret polymer films by soil microorganisms is different. Strength of the non-electret film after burial is increasing at first due to aging of the polymer (secondary crystallization, cross-linking of macromolecules) and is reducing afterwards exponentially as a result of biological damage. Strength of the electret films decreases immediately after burial in soil, because in the competition of polymer aging and accumulation of biodamages in the film the latter process is prevailing. This is why the destruction of the electret films by soil microorganisms takes less time.
The production of the electret films is ecologically friendly and needs no extra expenses. The films obey the rigid requirements of biodegradability imposed on packaging materials in majority of countries. Commercialization of the electret packaging films may alleviate significantly the problem of the polymer waste recovery.

\section{Acknowledgments}

This project was supported by National Academy of Sciences of Belarus: State program of scientific researches, grant No 20066783; Foundation of fundamental researches, grant No T06M-165.

\section{References:}

1. Haux V (2008) Polymer packing progress and new ability for waste packing utilization. Polymer Materials: Products, Equipment, Technology, 4, 2008, 12-15.

2. Petov NA (2008) Assessment of polymer waste accumulation in Russia and means of its recycling. Polymer Materials: Products, Equipment, Technology, 4, 2008, 4-7.

3. Scott G (1997) Abiotic control of polymer biodegradation. Trends in Polymer Science, 5 (11), 1997, 361-368.

4. Williams JR (2007) Life cycle analysis of bioplastics. Proceedings of the $9^{\text {th }}$ Annual Bioplastics Conference "Bioplastics-2007”, Koeln, 2007, 20-25.

5. Arutchelvi J (2008) Biodegradation of polyethylene and polypropylene / J. Arutchelvi M. Sudhakar, A. Arkatkar, M. Doble, S. Bhaduri, P.V. Uppara. Indian Journal of Biotechnology, 07 (1), 2008, 9-22. ISSN: 09750967 (Online); 0972-5849 (Print).

6. Toensmeier PA (2012) Biodegradable polymers make small-scale return. Modern Plastics International, 4, 1995, 19-21.

7. Avérous L (2012) Biodegradable Polymers. In L. Avérous, E. Pollet (Eds.) Environmental Silicate Nano-biocomposites, 2, London: Springer-Verlag, 2012, 13-40. ISBN: 978-14471-4101-3.

8. Kolybaba M (2003) Biodegradable Polymers: Past, present, and future / M. Kolybaba, L.G. Tabil, S. Panigrahi, W.J. Crerar, T. Powell, B. Wang. An ASAE Meeting Presentation, Paper No RRV03-0007, St. Joseph, Michigan, 2003.

9. Netravali AN (2003) Composites get greener / A.N. Netravali, S. Chabba. Materials Today, 4, 2003, 22-29.
10. Goncharova EP (2006) Modern trends in creation of biodegradable polymer materials / E.P. Goncharova, O.A. Ermolovich, L.S. Pinchuk, V.E. Sytsko. Material Science, 9, 2006, 37-43.

11. Avérous L (2014) Nanobiocomposites based on plasticized starch / L. Avérous, E. Pollet. In P. Halley, L. Avérous (Eds.) Starch polymers: From genetic engineering to green applications, 8. New York: Elsevier, 2014, 211239. ISBN: 978-0-444-53730-0

12. Averous L (2004) Biodegradable multiphase systems based on plasticized starch: a review. Journal of Macromolecular Science, Part CPolymer Review, 44(3), 2004, 231-274.

13. Zhang L (2008) Proteins as sources of materials / L. Zhang, M. Zeng. In M. Belgacem, A. Gandini (Eds.) Monomers, polymers and composites from renewable resources. Amsterdam: Elsevier, 2008, 479-493.

14. Santulli C (2016) Biopolymers directly developed from biomasses from agrowaste sources / C. Santulli, D. Puglia, J.M. Kenny. In V.K. Thakur, M.K. Thakur (Eds.) Handbook of Sustainable Polymers: Structure and Chemistry, 13. Pan Stanford Publishing Pte. Ltd., 2016. ISBN 9789814613552 - CAT\# N11244.

15. Okada M (2002) Chemical syntheses of biodegradable polymers. Progress in Polymer Science, 27 (1). Oxford, 2002, 87-133.

16. Philip S (2007) Polyhydroxyalkanoates: biodegradable polymers with a range of applications / S. Philip, T. Keshavarz, I. Roy. Journal of Chemical Technology and Biotechnology, 82(3), 2007, 233-247.

17. Navarro-Baena I (2015) Biodegradable nanocomposites based on poly(ester-urethane) 


\begin{tabular}{|c|c|c|c|c|c|c|}
\hline Impact Factor: & $\begin{array}{l}\text { ISRA (India) } \\
\text { ISI (Dubai, UAE } \\
\text { GIF (Australia) } \\
\text { JIF }\end{array}$ & $\begin{array}{l}=1.344 \\
=0.829 \\
=0.564 \\
=1.500\end{array}$ & $\begin{array}{l}\text { SIS (USA) } \\
\text { PИНЦ (Russia) } \\
\text { ESJI (KZ) } \\
\text { SJIF (Morocco) }\end{array}$ & $\begin{array}{l}=0.912 \\
=0.234 \\
=1.042 \\
=2.031\end{array}$ & $\begin{array}{l}\text { ICV (Poland) } \\
\text { PIF (India) } \\
\text { IBI (India) }\end{array}$ & $\begin{array}{l}=6.630 \\
=1.940 \\
=4.260\end{array}$ \\
\hline
\end{tabular}

and nanosized hydroxyapatite: Plastificant and reinforcement effects / I. Navarro-Baena, M.P. Arrieta, A. Sonseca, L. Torre, D. López, E. Giménez, J.M. Kenny, L. Peponi. Polymer Degradation and Stability, 121, 2015, 171-179.

18. Othman SH (2014) Bio-nanocomposite materials for food packaging applications: Types of biopolymer and nano-sized filler. Agriculture and Agricultural Science Procedia, 2, 2014,296-303.

19. John MJ (2008) Biofibres and biocomposites / M.J. John, S. Thomas. Carbohydrate Polymers, 71(3), 2008, 343-364. DOI: 10.1016/j.carbpol.2007.05.040. Source: OAI

20. Psomiadou E (1997) Biodegradable films made from low-density polyethylene, rice starch and potato starch for food packaging applications: Part 1 / E. Psomiadou, I. Arvanitoyannis, C.G. Biliaderis, H. Ogawa, N. Kawasaki. Carbohydrate Polymers, 33, 1997, 227-242.

21. Arvanitoyannis I (1998) Biodegradable films made from low-density polyethylene (LDPE), rice starch and potato starch for food packaging applications: Part 2 / I. Arvanitoyannis, C.G. Biliaderis, H. Ogawa, N. Kawasaki. Carbohydrate Polymers, 36, 1998, 89-104.

22. Shah PB (1995) Environmentally degradable starch filled low density polyethylene / P.B. Shah, S. Bandopadhyay, J.R. Bellare. Polymer Degradation and Stability. 47, 1995, 165-173.

23. Sessler GM (1987) Electrets. Topics in Applied Physics, Vol. 33, 2 ${ }^{\text {nd }}$ Ed. / G.M. Sessler, Ed. Berlin: Springer Verlag, 1987. - 385 p.

24. Pinchuk LS (1998) On the charge state of meltblown polymer materials / L.S. Pinchuk, A.G. Kravtsov, Yu.I. Voronezhtsev, Yu.V. Gromyko. International Polymer Processing, 13, 1998, 67-70.

25. Pinchuk LS (2003) Spontaneous polarization of polymer blends / L.S. Pinchuk, V.A. Goldade,
A.G. Kravtsov, S.V. Zotov, B. Jurkowski, K. Kelar. Polymer, 44 (17), 2003, 5031-5037.

26. Kestelman V (2000) Electrets in Engineering: Fundamentals and Applications / V. Kestelman, L. Pinchuk, V. Goldade. Boston: Kluwer Academic Publishers, 2000.

27. Korotki MV (2004) Polymer carriers of microorganisms as a source of biogenic elements / M.V. Korotki, A.V. Makarevich, L.S. Pinchuk. Materials Science, 11, 2004, 5256.

28. Pinchuk LS (2003) Electret-thermal analysis of polymer blends / L.S. Pinchuk, V.A. Goldade, A.G. Kravtsov, S.V. Zotov, B. Jurkowski, K. Kelar. International Polymer Processing, 18 (2), 2003, 151-155.

29. Pinchuk LS (2002) Electret-thermal analysis of blood / L.S. Pinchuk, V.A. Goldade, G.M. Sessler, A.G. Kravtsov, S.V. Zotov, E.A. Tsvetkova. Medical Engineering and Physics, 24, 2002, 361-364.

30. Chandra R (1997) Biodegradation of maleated linear low-density polyethylene and starch blends / R. Chandra, R. Rustgi. Polymer Degradation and Stability, 56, 1997, 185-202.

31. Rogovina SZ (2000) A study of cellulosechitosan blends obtained under shear strain / S.Z. Rogovina, T.A. Akopova, G.A. Vikhoreva, I.N. Gorbacheva, A.A. Zharov, A.N. Zelenitsky. Polymer Science, 42A, 2000, 10-15.

32. Dechant J (1972) Ultrarotspektroskopische Untersuchungen an Polymeren / J. Dechant, R. Danz. Berlin: Akademie-Verlag, 1972.

33. Pinchuk LS (2004) Electret-thermal analysis to assess biodegradation of polymer composites / L.S. Pinchuk, A.V. Makarevich, G.M. Vlasova, G.A. Kravtsov, V.A. Shapovalov. International Biodeterioration and Biodegradation, 54, 2004, 13-18. 